\title{
Designing a Solar Powered Automatic Hand-Dryer to Combat the Outbreak of Ebola and Monkey Pox Diseases in Sub-Saharan Africa
}

\author{
${ }^{1}$ OKPEKI, UK; ${ }^{2}$ OYUBU, AO; ${ }^{3} \mathrm{OYUBU}, \mathrm{AU}$ \\ ${ }^{1,2}$ Department of Electrical and Electronics Engineering, Delta State University, Abraka, Oleh Campus, Delta State, Nigeria. \\ ${ }^{3}$ University Health Services, Delta state University, Abraka. Delta State, Nigeria. \\ *Corresponding Author Email: ufuomakazeem@gmail.com,akposweet@yahoo.com; akpesweet@yahoo.com
}

\begin{abstract}
In recent times, the outbreak and the concomitant spread of Monkey pox and Ebola virus diseases across some countries of sub-Saharan Africa in electrifying waves was terrifying. The countries worst hit are Liberia, Sierra Leone, Ghana, and Nigeria. The outbreaks which were earlier recorded in 1953 and contained suddenly resurfaced in 2013 and 2017 respectively but to this day, the medical profession has not been able to proffer a cure to these deadly diseases. A major mode of transmitting these diseases is through contact with an infected person especially by touching such persons; hence, washing/sanitizing of hands has become a standard preventive practice over the years. One effective means of hand sanitization is the use of a hand-dryer which not only dries a wet hand after washing but also has the ability to kill germs through the hot air of about $53^{\circ} \mathrm{C}$ it produces. Available hand-dryers are $\mathrm{AC}$ powered; as such, they cannot be used in areas where there is no electricity or where electricity supply is erratic like many sub-Saharan African countries. Consequently, the design and implementation of a solar powered hand-dryer becomes imperative since these deadly diseases have no known cure at the moment but can be prevented by applying appropriate preventive measures. The design contains primarily two sections-the solar power section which comprises circuits /components that function together to charge the batteries that power the hand-dryer system, and the hand-dryer section that comprises the transmitter/ receiver circuit, the heater, the fan and other components that work together to make the hand-dryer section function properly. Every stage of the design was tested for performance before the system was assembled. The design was implemented and it functioned according to design objective.
\end{abstract}

\section{DOI: https://dx.doi.org/10.4314/jasem.v22i10.08}

Copyright: Copyright $\odot 2018$ Okpeki et al. This is an open access article distributed under the Creative Commons Attribution License (CCL), which permits unrestricted use, distribution, and reproduction in any medium, provided the original work is properly cited.

Dates: Received: 05 September 2018; Revised: 17 October: 2018; Accepted: 22 October 2018

Keywords: Ebola, Monkey pox, Solar, hand-dryer, disease.

The Monkey virus was first discovered in 1959 when two outbreaks of a pox-like disease occurred in colonies of money kept for research, hence the name "monkey pox" (Sola, 2017). The first recorded human case of money pox was recorded in 1970 of Congo in sub-Saharan Africa. The current outbreak in Nigeria is of West Africa Origin and associated with milder disease, fewer deaths and limited human-to-human transmission. The Ebola outbreak in sub-Saharan Africa was first reported in March, 2014 and rapidly became the deadliest occurrence of the disease since its discovery in 1979, and at the moment the medical profession has not proffered cure to these deadly diseases, only preventive measures (sanitation) are still being applied. A popular preventive measure taken to curb the spread of diseases from time immemorial is hand-washing. In eateries, hotels and other institutions where hand-washing is practiced, a hand dryer which is electrically operated is installed to replace the use of public hand towels which becomes a breeding ground for diseases after a time. This has helped in no small way in curbing the spread of diseases. However with the present poor developmental state of sub-Saharan region of Africa and the failure of government to provide modern infrastructures and steady power supply in towns /cities, rural areas and public toilets/baths that are either not connected to the national grid or who do not have alternative energy sources when there is power outage, benefiting from the use of the hand-dryer after washing becomes impossible. To this end, the designing, implementation and deployment of a solar powered hand dryer system becomes absolutely imperative for a proper hand sanitation which will ultimately curb/combat the spread of communicable diseases especially, ebola and monkey pox diseases to mention but a few. The hand-dryer operates within $50^{\circ} \mathrm{C}-65^{\circ} \mathrm{C}$, the temperature range that is high enough to kill germs. Several studies have been carried out over five decades to investigate the effectiveness of hand drying systems in the content of skin hygiene. (Benol, 2007) carried out a comparative study on various hand drying systems with regards to their hygiene performance. And the various results obtained were translated and applied to product design context. (Matthews and Newsom 1987) examined the bacterial aerosols released from hands during hot air dryer usage, compared with those released by paper towels. 
Impression plates-hand imprints on agar plates after drying revealed that similar numbers of bacteria were present in the hand by either methods, and that hot air hand dryers appear safer from bacteriological viewpoint. (Ansari et al., 1991) carried out a comparative study of the efficiencies of paper, cloth and electric warm air drying in eliminating viruses and bacteria from washed hands and discovered that, irrespective of the hand-washing agent used, the electric air drying system produced the highest reduction in numbers of both viruses and bacteria. (Hareendran,2014) constructed automatic hand dryer machine with temperature display, to eliminate the dangers and problems associated with the manual process, like contracting diseases with the use of the same hand towels by many people in restaurants and our health care facilities. He designed his system with active and passive component sensors (LM35 \& LDR). His work was pure hand-wired, no use of micro program controls. (Stephen, 2018) the author designed a microcontroller based automatic hand dryer system. In his design he used both hardware and software, the hardware components are coordinated by AT89S51 microcontroller chip while the programs are embedded in the chip. Hand hygiene has the potential to prevent diseases and reduce health care associated infections. And proper drying of hands after washing is an essential component of effective hand hygiene procedures. In view of the above (Cunrui et al., 2012) carried out a systematic review of research works and analyzed the hygienic efficacy of different hand drying methods. (Montalbol et al., 2011) carried out a study that compared seven different hand-drying methods by performing life cycle analysis on each-system. Their work showed that the hot air dryer is most suitable. Rochester Institute of Technology investigated the environmental impacts of paper towels versus those of hand dryers in a college campus via life cycle analysis. Their findings showed that the use of the Dyson dryer reduced the environmental impact and carbon footprint and also more economical. The objective of this paper is to design a solar powered automatic handdryer to combat the spread of Ebola and Monkey pox diseases.

\section{MATERIALS AND METHOD}

The prime objective of this work is to design and implement a solar powered hand-dryer. The use of solar technology in powering the hand-dryer is predicated on its economic value since solar energy is very readily available and in abundance in subSaharan Africa. The ease of the dryer's deployment in off-grid locations is also worthy of note. The overall system contains two main sections - the Solar Power section which consists of: Solar Panel, Charging Circuit, Battery and a Voltage regulator, and the handdryer circuit section which is made up of infrared proximity detector, control switch, electric heater, electric fan and hot air tunnel. The system block diagram is as shown below:

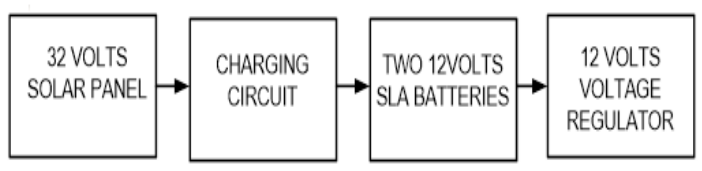

Fig 1: Solar power section block diagram

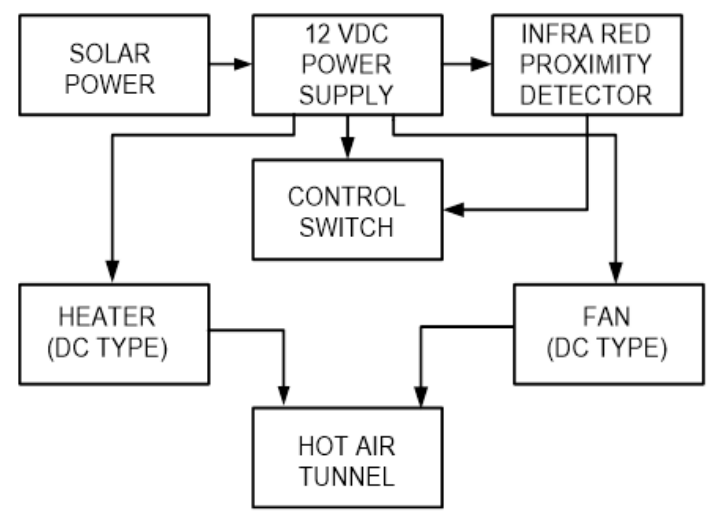

Fig 2: Overall circuit block diagram

Solar Power Section: The Solar Power Section which is essentially the power supply unit of the designed system was realized using the following components: a solar panel, diode, LM317T adjustable voltage regulator, capacitors, BC548 transistor, resistors and LM7812 voltage regulator. The various components were electrically connected together to realize the power section of the system.

Solar Panel: In this work, the solar panel is required to charge two $12 \mathrm{~V}$ 7.2Ah SLA batteries connected in series through a voltage regulator. From the battery specifications, a voltage in the range of $(14.4 \mathrm{~V}-15 \mathrm{~V})$ is needed to charge one the batteries for one cycle use; therefore a voltage in the range of $(28.8 \mathrm{~V}-30 \mathrm{~V})$ is required. Also a voltage regulator is required to stabilize the charging voltage, this regulator has a forward voltage drop of $2 \mathrm{~V}$. The diode to protect the solar panel and the voltage regulator from reverse voltage also has a voltage of $0.7 \mathrm{~V}$.

Using $\mathrm{V}_{\text {Out }}=\mathrm{V}_{\mathrm{Cyc}}+\mathrm{V}_{\mathrm{tf}}$

Where $\mathrm{V}_{\text {Out }}=$ Solar Panel Voltage, $\mathrm{V}_{\text {Cyc }}=$ Battery Cycle, Charge Voltage and $\mathrm{V}_{\mathrm{tf}}=$ Total forward Voltage drop.

A 36V Solar Panel was chosen for the work.

Protection Diode: The protection diode is used to protect the solar panel from damage due to reverse voltage; it is also used to protect both the voltage regulator and capacitor from reverse connection of the solar panel. 
Table I: Performance result obtained from each stage

\begin{tabular}{|c|c|}
\hline STAGES & PERFORMANCE RESULTS \\
\hline Solar power section: & $\begin{array}{l}36.3 \mathrm{~V} \text { was read from the solar panel while still under direct sunlight. This shows that the solar } \\
\text { panel is active and functioning optimally. }\end{array}$ \\
\hline Solar panel & $\begin{array}{l}\text { Voltage was deliberately reversed, solar connection was reversed, thus; there was no current } \\
\text { flowing under this condition. This shows that the protection diode is functioning well. }\end{array}$ \\
\hline Protection diode & $\begin{array}{l}\text { The voltage regulators,LM } 312 \mathrm{~T} \text { and } 7812 \text {, supplied } 30 \mathrm{~V} \text { and } 12 \mathrm{~V} \text { respectively as prescribed } \\
\text { when performance test was carried out on them }\end{array}$ \\
\hline The hand-dryer section: & $\begin{array}{l}\text { Each time the transmitted signal from the transmitter to the receiver was deliberately } \\
\text { interrupted by placing an obstacle between the transmitter and the receiver thereby disrupting } \\
\text { the line of sight (LOS) during the performance test, the receiver was triggered, thus } \\
\text { activating the transistor-relay switch combination (a part of the receiver) which switched } \\
\text { 'ON' two LEDs connected as loads simultaneously. This simply shows that the transmitter } \\
\text { performance is excellent }\end{array}$ \\
\hline & $\begin{array}{l}\text { The triggering of the receiver and the resulting activation of the transistor-relay switch } \\
\text { combination (a part of the receiver) which switched 'ON' two LEDs connected as loads } \\
\text { simultaneously shows that the receiver is active. }\end{array}$ \\
\hline The infra-red receiver & $\begin{array}{l}\text { The two LEDs connected as load remained 'ON' for } 25 \text { seconds each time there was } \\
\text { triggering; thus confirming that the delay stage is performing in consonance with design } \\
\text { objective. }\end{array}$ \\
\hline Time delay stage & $\begin{array}{l}\text { This stage performed optimally as heat and air were simultaneously produced whenever the } \\
\text { heater and fan were simultaneously activated by the transistor-relay switch combination } \\
\text { whenever there was triggering. }\end{array}$ \\
\hline Heater and Fan control & \\
\hline
\end{tabular}

The solar panel chosen for this work has an open circuit voltage of $45.5 \mathrm{~V}$. Thus an IN4007 diode was chosen with maximum voltage with rating from $50 \mathrm{~V}-$ $1000 \mathrm{~V}$.

Voltage Regulator: Dual Voltage regulators were used in this work. While one, LM317T is used to supply $30 \mathrm{~V}$ to charge the batteries, the other, 7812 supplies a steady $12 \mathrm{Vdc}$ to drive the system.

The hand-dryer section: The hand-dryer section of this work consists of the following designed stages/units. The infrared transmitter stage, the infrared receiver stage, the time delay stage and heater and fan control stage. These various stages/units were electrically linked after they were designed to realize the hand dryer section.

The Infrared Transmitter: This circuit was made from an astable 555timer multivibrator and an Infrared LED driver which serves as the transmitter. The astable multivibrator is set using the relevant capacitors and resistors to generate a frequency of $38 \mathrm{KHZ}$.

The Infrared Receiver: This circuit which is mainly a photodiode with current limiting resistors and noise reducing capacitors connected to it serves to receive infrared signals from the transmitter. The infrared 
receiver is connected to a 555 timer monostable multivibrator.

Time Delay Stage: This segment of the design is designed to generate a fixed control pulse-width of 25 seconds. This is so done to enable the wet hand to dry and also elongate the life span of the heating element.

Heater and Fan Control Stage Section: This section/stage controls power to the heating element, which is a dc type heating element, and the fan which is also a dc fan of $5 \mathrm{~W}$. The heater and fan are powered from the dc battery directly. This section consists mainly of a transistor-relay switch combination, the heater and fan.

Mode of Operation: This work, the design and implementation of a solar powered automatic handdryer is a $12 \mathrm{Vdc}$ operated system which supplies a steady $12 \mathrm{Vdc}$ through a 7812 voltage regulator to a 555 timer multi-vibrator. This 555 timer astable multivibrator generates $38 \mathrm{KHZ}$ which drive the infrared transmitter. The infrared transmitter sends signal constantly to a photo diode receiver which is connected to a 555 timer monostable multi-vibrator which produces a single pulse whenever the transmitted signal from the infrared to the receiver is interrupted. This interruption triggers the system. Whenever the system is triggered, the system is powered on, and the 555 timer mono stable multivibrator activates the relay which acts as a switch and activates the heating element and the fan simultaneously. The fan blows warm air of $55^{\circ} \mathrm{C}$ for 25 seconds after which it automatically switches off until the next time the system is triggered via the interruption to the infrared signal.

\section{RESULTS AND DISCUSSION}

From the table above, it can be seen that every stage of the design plays a paramount role in achieving the overall design objective; thus, every stage was carefully tested to ascertain their level of performance before transferring them to a vero board and electrically linked to form the desired system-the solar powered hand-dryer. The infra-red receiver and transmitter (Proximity detector) besides triggering the system also ensures that the users do not have to use their hands to operate a power button as obtained in some models of hand-dryers before drying their hands. This in itself is a preventive measure.

Conclusion: The designing of a solar powered automatic hand dryer system was successfully done. Unlike the existing ones, this design does not rely on $\mathrm{AC}$ power as its source of power; rather, it is powered with solar energy which is abundant and readily available in sub-Saharan Africa. This makes it an improvement on existing hand-dryers. Thus it can be deployed in public places, homes and rural areas within sub-Saharan Africa where electricity supply has become almost non-existent. This will in no small measure help to combat the spread of Ebola and monkey pox virus diseases.

Acknowledgement: We wish to specially appreciate $\mathrm{Dr}$ (Mrs) Oyubu, A.U of the Delta State University health services, Abraka for her invaluable contribution to this work. Our colleagues at the department of Electrical/Electronic Engineering, Delta state University, Oleh campus are also appreciated for their inputs.

\section{REFERENCES}

Ansari, SA; Springthorpe, SV; Satter, SA; Tostowaryk, W; Well, GA (1991). Comparison of Cloth, Paper and Warm air drying in eliminating viruses and bacteria from washed hands. Am. J. Infect. Cont. 19(5):243-249.

Bezerra, AS (2007). Economic viability analysis of replacing paper towels by electric hand dryers in public restrooms. Revista Ciências do Ambiente On-Line. 3(1):1-6.

Bonol, JW (2007). International Association of Societies of Design Research. The Hong Kong Polytechnic University.

Huang, C; Wenjun, MA; Stack, S (2012).The Hygiene Efficacy of different Hand drying Methods. Mayo Clinic Proceedings. 87(8):791-798.

Hareendran, TK (2014).Design and Construction of automatic hand dryer with temperature display.www.electroschematics.com//1040/autom atichand-dryercircuit

Matthews, JA; Newsom, SWB (1987). Hot air electric dryers compared with paper towels for the potential spread of airborne bacteria. J. Hos. Infect. 9(1): 8588.

Moltalbo, T; Gregory, J; Kirchain, R (2011). Life Cycle Assessment of hand drying systems. Massachusetts Institute of Technology. http://msl.mit.edu/publications/handDryingLCH.

Ramos, RG; Filho, RCP; Lobo, RRS (2009). Analysis of the efficiency of electric dryers and paper towels for hand drying. 5(2):1-5. 
Rochester Institute of Technology (2013). Sustainable Hand Drying. www.rit.edu/affiliate/

nysp2i/sites/rit.edu.affiliate.nysp2i/files/12rdsc15_sus tainable_hand_drying.

Sola, Ogundipe (2017). http://www.vanguardngr.com. Monkey pox, $15^{\text {th }}$ October.
Stephen, R (2018).Microcontroller based automatic hand-dryer system. http://afribay.com/works/ Microcontroller-based-automatic-hand-dryersystem

Yamamoto, Y; Ugai, K; Takahashi, Y (2005). Efficiency of Hand Drying for Removing Bacteria From Washed Hands Comparison of Paper Towel Drying With Warm Air Drying. Infect. Cont. Hos. Epidemiol. 26(3):316-320. 